\title{
REVIEW
}

\section{Hyper-recombination and Bloom's Syndrome: Microbes Again Provide Clues about Cancer}

\section{Rodney Rothstein ${ }^{1}$ and Serge Gangloff}

\author{
Department of Genetics and Development, Columbia University College of Physicians and Surgeons, \\ New York, New York 10032
}

Once again, a gene family first identified in microorganisms has been linked to human cancer predisposition. The first in a series of intriguing links between microbial genetics and tumorigenesis in man emerged when the genes responsible for xeroderma pigmentosum were identified as homologs of yeast DNA repair genes (for review, see Cleaver 1994; Tanaka and Wood 1994). Another link surfaced 2 years ago with the identification of human colorectal cancer susceptibility and mutations in a homolog of a bacterial and yeast mismatch repair gene (Fishel et al. 1993; Parsons et al. 1993). Earlier this year, the gene responsible for ataxia-telangiectasia was identified as a member of a kinase gene family that may play a role in DNA damage recognition (Greenwell et al. 1995; Hari et al. 1995; Morrow et al. 1995; Savitsky et al. 1995). The latest link is the identification of the Bloom's syndrome gene, $B L M$ (Ellis et al. 1995a). BLM encodes a protein homologous to the RecQ/Sgs1 DNA helicase subfamily first identified in bacteria and yeast (Umezu et al. 1990; Gangloff et al. 1994). Mutations in BLM and in the yeast homolog SGS1 confer the common phenotype of hyper-recombination to cells.

Hyper-recombination collectively refers to any cellular state in which the frequency of genetic exchange is elevated. The exchanges can occur, for example, between sister chromatids, allelic genes, or repetitive DNA sequences scattered throughout the genome. The frequency of recombination can be measured genetically between marked intervals and also cytologically as deletions, inversions, translocations, sister chromatid exchanges, and somatic crossovers. In this review we limit our discussion to mutations in

\footnotetext{
'Corresponding author.

E-MAIL rothstein@cuccfa.ccc.columbia.edu; FAX (212) 923
} 2090. microbes and man that specifically increase recombination.

\section{Bloom's Syndrome}

Bloom's syndrome, originally identified as a distinct erythematous facial rash (Bloom 1954), is inherited as an autosomal recessive trait. In addition, individuals affected with Bloom's syndrome are characterized by growth retardation, abnormal spermatogenesis, and an elevated risk of developing cancer (German 1993). Besides these clinical manifestations, cells from individuals with Bloom's syndrome exhibit elevated levels of chromosome breaks and gaps, somatic crossovers, and sister chromatid exchange (German 1993).

Genetic experiments with Bloom's syndrome cell lines showed that transfer of chromosome 15 could complement increased sister chromatid exchange. Further refinements in the genetic map localized the defective gene to a region near 15q26.1 (Ellis et al. 1994). An important breakthrough came when German's group found that they could exploit an early observation. They noticed that although most cells of individuals with Bloom's syndrome exhibit high sister chromatid exchange, there exists a minor population of lymphocytes with low sister chromatid exchange. Cells with low sister chromatid exchange were predominantly found in individuals whose parental alleles were not identical by descent and therefore contained different mutations in $B L M$. An intragenic crossover between the paternal and maternal alleles generated a wild-type gene on one chromosome and a gene containing both parental mutations on the homologous chromosome. After segregation, half of the recombined cell lines became homozygous for polymorphic markers distal to the $B L M$ locus, whereas they remained heterozygous for polymorphic markers 


\section{ROIHSIEIN AND GANGLOFF}

proximal to the locus (Ellis et al. 1995b). Thus, somatic crossover point mapping helped demarcate the boundaries of the gene and narrow down the chromosomal region. It is interesting to note that the hyper-recombinogenic nature of the $\mathrm{blm}$ mutation probably led to the high incidence of this somatic event. Then, using direct cDNA selection, a clone was isolated that mapped to the candidate region. Translation of the DNA sequence of this clone revealed motifs homologous to the RecQ/Sgs1 helicase subfamily (Ellis et al. 1995a).

\section{BLM and Sgsl May Be Homologs}

RecQ the founding member of a subfamily of DNA helicases, is a DNA-dependent ATPase that possesses a $3^{\prime} \rightarrow 5^{\prime}$ DNA translocation activity. It was first identified as a protein involved in the RecF recombination pathway in Escherichia coli (Umezu et al. 1990). The absence of RecQ in $E$. coli does not have any discernible phenotype unless a major recombination pathway (RecBCD, SbcBC) is mutated (Clark 1991). In this situation, loss of RecQ function leads to UV sensitivity and to a decrease in recombination. Recently, the RecQ subfamily of helicases has grown. A human helicase, RECQL, was identified biochemically and was shown to possess the same in vitro properties as bacterial RecQ (Puranam and Blackshear 1994). Cloning and sequence analysis revealed

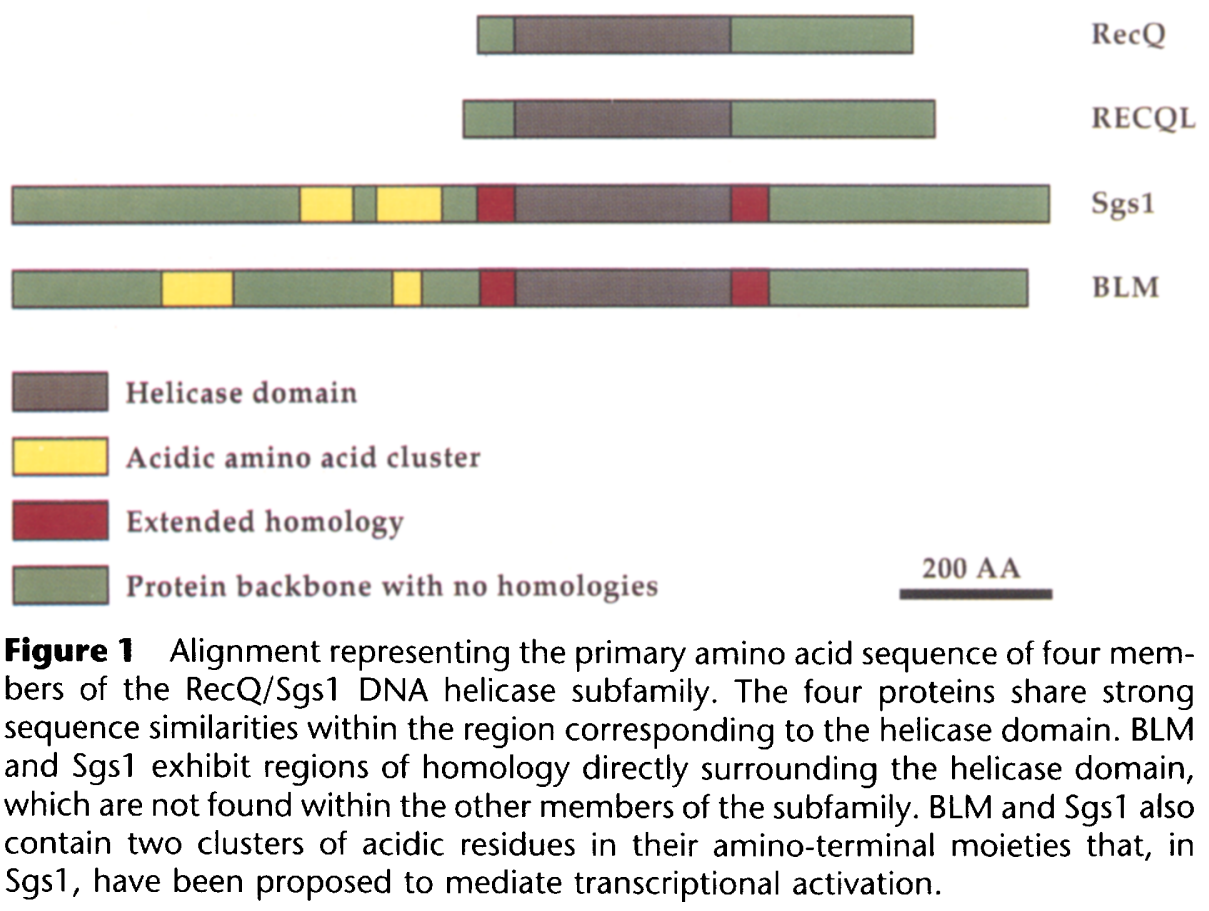

that its protein sequence shared significant homology with bacterial RecQ. In addition, another RecQ homolog has been identified as a result of the Caenorhabditis elegans sequencing project (GenBank no. U00052, K02F3.1). To date, no disease mapping to the human RECQL gene homolog has been reported. For $C$. elegans, the phenotype of mutants is also unknown. In both of these cases, the homology shared with RecQ is restricted to the seven conserved helicase motifs.

BLM is also homologous to Sgs 1 , a yeast protein (Gangloff et al. 1994). On the basis of a comparison of their primary structure, four lines of evidence suggest that BLM may be the human homolog of Sgs1 (see Fig. 1). First, unlike what is observed for RecQ and RECQL, the sequence similarity between BLM and Sgs1 extends beyond the helicase domains. Second, the size of the two proteins are nearly identical, more than twice the size of the other RecQ family members. Third, the conserved helicase domain is in the same position in the two proteins, situated $\sim 700$ amino acids from the amino terminus. Lastly, the amino-terminal domain of BLM contains two clusters of charged amino acid residues paralleling the Sgs1 organization. In addition to the structural similarities of BLM and Sgs1, blm and sgs1 mutant cells both exhibit increased levels of mitotic recombination. In yeast cells, hyperrecombination is manifested by an increased frequency of marker loss. In Bloom's cells, it is revealed by increased sister chromatid exchange and symmetrical quadriradials, which probably represent exchange figures between homologous chromosomes in metaphase (German 1964). On the other hand, recQ mutants exhibit decreased levels of recombination.

\section{Sgsl May Provide Clues to BLM Function}

First identified as an extragenic suppressor of the slow-growth phenotype of topo III-deficient mutants, the SGS1 locus was shown to interact physically with both topo II 
and topo III (Gangloff et al. 1994; Watt et al. 1995). As both of these DNA topoisomerases are potentially involved in the resolution of replication intermediates (Wang 1991; Fig. 2), it is tempting to speculate that Sgs1 differentially modulates their activity. For example, in the absence of Sgs1, the failure to resolve the intertwined strands generated at the point where replication forks merge would give rise to recombinogenic lesions (e.g., breaks) in a newly replicated chromatid. Repair of such lesions, using information from the sister chromatid, could lead to a sister chromatid exchange event (Fig. $3 \mathrm{~A})$. Alternatively, a cell could repair the damaged chromatid using information on the homologous chromosome resulting in a mitotic exchange (Fig. 3B). In the mitotic division following such an exchange, DNA distal to the

\section{MICROBIAL CLUES ABOUT CANCER PREDISPOSITION}

crossover can become homozygous, resulting in loss of heterozygosity.

\section{Hyper-recombination and Cancer}

A few human disorders have been associated with increased levels of chromosomal rearrangements (see Table 1). A common facet of these "hyperrecombination" syndromes is their high cancer risk. Table 1 also lists selected genes from bacteria and yeast that show increased recombination (Hartwell and Smith 1985; Barnes et al. 1992; Gangloff et al. 1994; Kato and Ogawa 1994; Morrow et al. 1995; Savitsky et al. 1995; Smith and Rothstein 1995). In bacteria, many of these genes were identified using a simple assay in which recombination between direct repeats leads to a selectable phenotype (Konrad 1977). The fre-
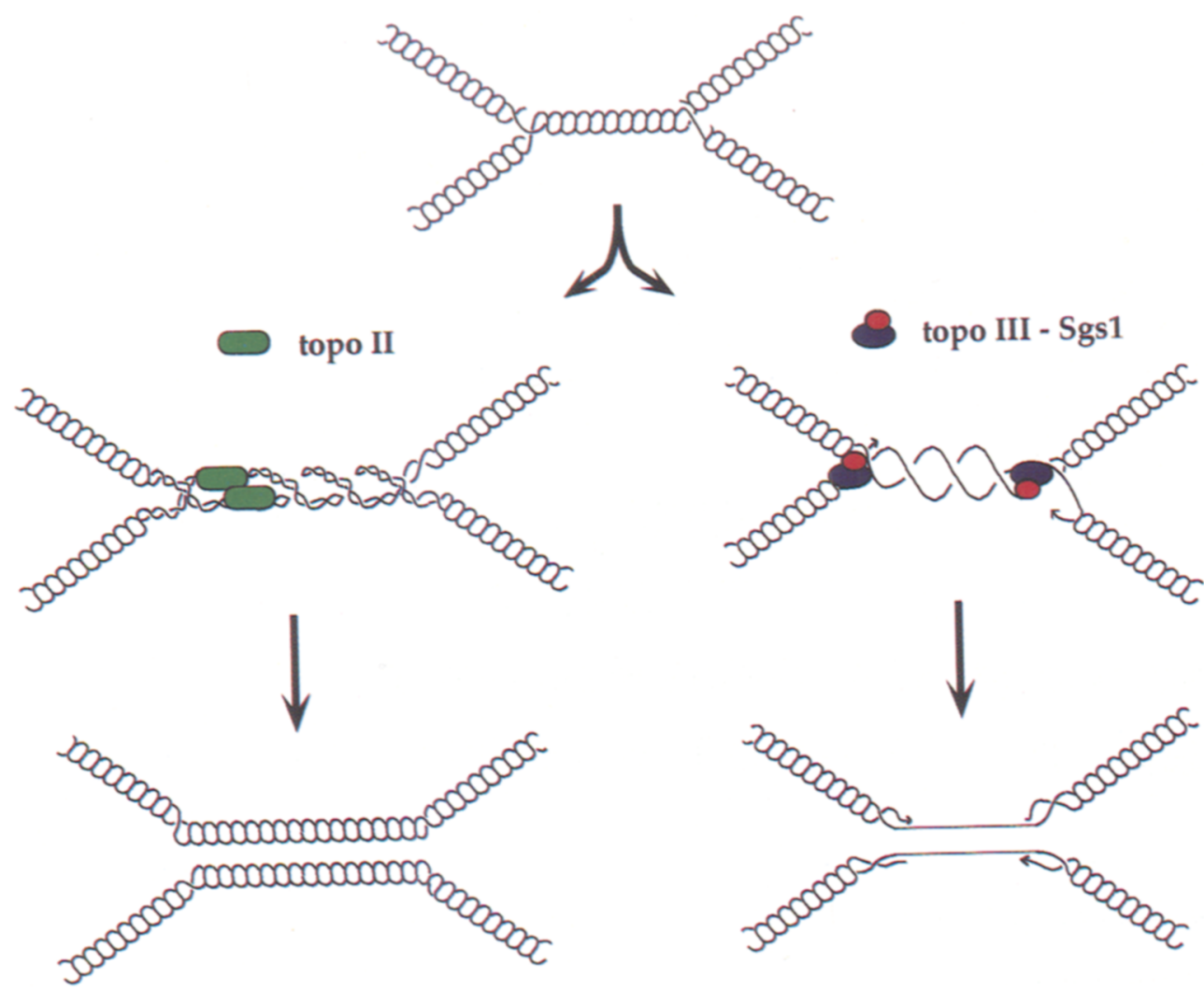

Figure 2 Resolution of merging replicons. Two pathways have been proposed for the resolution of intertwined strands found at the site of merging replication forks (Wang 1991). As the two replicons approach one another, topological constraints block the merging forks leaving a small stretch of unreplicated duplex. In the pathway shown at left, DNA synthesis proceeds using the leading strands from both replication forks and the DNA is converted into two intertwined duplexes that are decatenated by topo II. In the pathway at right, replication is arrested until the single strands are separated by the combined action of the helicase activity of Sgs 1 and the decatenation activity of topo III. In this model the Sgs1 helicase tracks along the unreplicated stretch and the associated topo III decatentates the exposed single strands. DNA synthesis is completed by filling in the singlestrand gaps. For the sake of clarity, only a few intertwines are depicted. (Adapted from Wang 1991.) 


\section{ROTHSIEIN AND GANGLOFF}

A

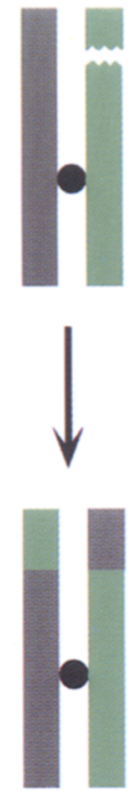

SCE
B
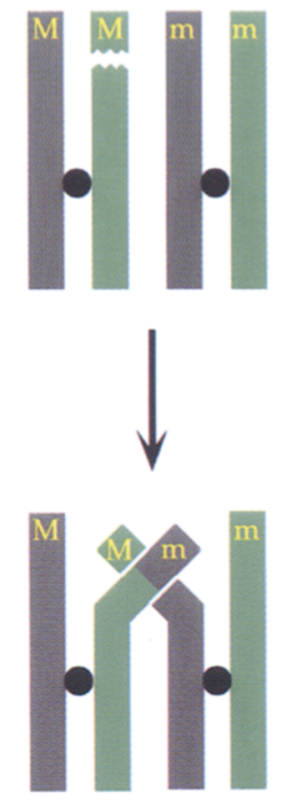

Recombination between homologs

Figure 3 Recombinational repair of a DNA lesion. The DNA lesion is depicted simply as a doublestrand break for purposes of illustration. In both cases, the repair is shown associated with a crossover. (A) Repair of the lesion by homologous recombination between sister chromatids. (B) Repair of the lesion by homologous recombination between homologs. The letters $M$ and $m$ indicate a distal heterozygous gene. Because mitotic segregation of the replicated chromatids into the daughter cells can produce two outcomes, after a crossover, onehalf of the segregations generate a cell in which the distal marker has lost its heterozygosity.

quency of this event can be estimated easily and permits the screening of large numbers of individual mutagenized colonies for an altered frequency of recombination. Similarly, most of the hyper-recombination mutations in yeast were isolated using either natural or artificially created direct repeat recombination assays (for review, see Klein 1995). Recently, a similar strategy has been employed in cell lines derived from patients with ataxia-telangiectasia (Meyn 1993) or Werner syndrome (Monnat 1992) .

It has been estimated that most individuals, either as a result of somatic mutation or inheritance, are mosaic for cells that are heterozygous for tumor suppressor genes (Loeb 1991). It is only when loss of heterozygosity occurs for one of these genes that the progression toward tumori-

genesis begins (for review, see Knudson 1991). Thus, any mutation that results in an increase in mitotic recombination can potentially lead to an increase in the frequency of homozygosity of one of these recessive genes.

\section{Increased Incidence of Cancer in blm Heterozygotes?}

Finally, it is interesting to note that some recessive genes, such as retinoblastoma and $h m s h 2$, give rise to cancer as if they were dominant traits when pedigrees are analyzed. This is owing to loss of heterozygosity at the cellular level. In the case of retinoblastoma, any loss of the wild-type copy by a variety of mechanisms, including recombination between homologs, leads to a cell that has lost growth control. Similarly, in hmsh2associated colorectal cancers, loss of the unaffected gene causes increased DNA slippage during replication generating subsequent mutational events that lead to cancer. Therefore, individuals heterozygous for blm may also show an increased incidence of cancer. This would occur in two steps: loss of the unaffected BLM gene followed by loss of heterozygosity of a tumor suppressor gene. In this model, the frequency of the second event would be increased as a direct consequence of the blm phenotype in those cells. This hypothesis can be tested by measuring the occurrence of sporadic tumors within Bloom's syndrome families and by analyzing such tumors from heterozygous individuals to detect the homozygosity of blm.

\section{Conclusions}

The study of a basic biological phenomenon, genetic recombination, in simple microbial systems has led to the identification of many genes involved in DNA metabolism (Table 1). With the ability to rapidly identify the genes underlying human diseases that has been facilitated by the Human Genome Project, the corresponding human genes are starting to be identified. Although many insights will be gained from studying the homologous genes found in simpler organisms, it is clear that many questions remain. For example, the SGS1 gene was cloned as a result of twohybrid interactions with both topo II and topo III. Does the amino-terminal region of BLM similarly interact with topoisomerases to form a complex? Do sgs 1 mutants exhibit increased sis- 
MICROBIAL CLUES ABOUT CANCER PREDISPOSITION

\section{Table 1. Hyper-recombination Mutations}

\begin{tabular}{lll}
\hline Organism & Mutation & Gene product/function \\
\hline Escherichia coli & lig & DNA ligase \\
& polA & DNA polymerase \\
& uvrD & DNA helicase \\
Saccharomyces cerevisiae & topB & DNA topoisomerase \\
& $c d c 2, c d c 17$ & DNA ligase \\
& rad3, srs2, and sgs1 & DNA polymerase \\
& top1, top2, and top3 & DNA helicase \\
& ral & DNA topoisomerase \\
& esr1 (mec1) & DNA single-stranded binding protein \\
Homo sapiens & $46 \mathrm{BR}$ (immunodeficient patient) & DNA damage recognition? \\
& Bloom's syndrome & DNA ligase \\
& ataxia-telangiectasia & DNA helicase? \\
& Werner syndrome & DNA damage recognition? \\
\hline
\end{tabular}

This is not an exhaustive survey of all possible hyper-recombination mutations but only lists some whose gene products may be directly involved with DNA metabolism. The bacterial and yeast genes have been reviewed recently (Kline 1995). The human disorders are referenced in the text. It should be noted that a consensus has not been reached for the hyper-recombination phenotype of 46BR.

ter chromatid exchange? Finally, as shown in Table 1 , Werner syndrome is another human disease that may cause predisposition to cancer as a result of hyper-recombination. It will be interesting to see whether this disease is also attributable to a mutation in a gene affecting DNA metabolism.

\section{ACKNOWLEDGMENTS}

We thank D. Beach, F. Collins, N. Erdeniz, H. Klein, S. Lovett, S. Meyn, R. Monnat, U. Mortensen, V. Racaniello, J. Smith, L. Symington, and H. Zou for critical reading of the manuscript. We also thank N. Ellis and J. German for helpful suggestions on an earlier version of this manuscript. This work was supported by grants from the National Institutes of Health (GM34587 and GM50237) and National Science Foundation (DMB89191812) to R.R.

\section{REFERENCES}

Barnes, D.E., A.E. Tomkinson, A.R. Lehmann, A.D. Webster, and T. Lindahl. 1992. Mutations in the DNA ligase I gene of an individual with immunodeficiencies and cellular hypersensitivity to DNA-damaging agents. Cell 69: 495-503.

Bloom, D. 1954. Congenital telangiectatic erythema resembling lupus erythematosus in dwarfs. Am. J. Dis. Child. 88: $754-758$.

Clark, A.J. 1991. rec genes and homologous recombination proteins in Escherichia coli. Biochimie 73: $523-532$.

Cleaver, J.E. 1994. It was a very good year for DNA repair. Cell 76: 1-4.

Ellis, N.A., A.M. Roe, J. Kozloski, M. Proytcheva, C. Falk, and J. German. 1994. Linkage disequilibrium between the FES, D15S127, and BLM loci in Ashkenazi Jews with Bloom syndrome. Am. J. Hum. Genet. 55: 453-460.

Ellis, N.A., J. Groden, T.-Z. Ye, J. Straughen, D.J. Lennon, S. Ciocci, M. Proytcheva, and J. German. 1995a. The Bloom's syndrome gene product is homologous to RecQ helicases. Cell 83: 655-666.

Ellis, N.A., D.J. Lennon, M. Proytcheva, B. Alhadeff, E.E. Henderson, and J. German. 1995b. Somatic intragenic recombination within the mutated locus $B L M$ can correct the high SCE phenotype of Bloom's syndrome cells. Am. J. Hum. Genet. 57: 1019-1027.

Fishel, R., M.K. Lescoe, M.R.S. Rao, N.G. Copeland, J. Garber, M. Kane, and R. Kolodner. 1993. The human mutator gene homolog $\mathrm{MSH} 2$ and its association with hereditary nonpolyposis colon cancer. Cell 75: $1027-1038$.

Gangloff, S., J.P. McDonald, C. Bendixen, L. Arthur, and R. Rothstein. 1994. The yeast type I topoisomerase Top3 interacts with Sgs1, a DNA helicase homolog: A potential eukaryotic reverse gyrase. Mol. Cell. Biol. 14: 8391-8398.

German, J. 1964. Cytological evidence for crossing-over in vitro in human lymphoid cells. Science 144: 298-301. 


\section{ROIHSIEIN AND GANGLOFF}

1993. Bloom syndrome: A mendelian prototype of somatic mutational disease. Medicine 72: 393-406.

Greenwell, P.W., S.L. Kronmal, S.E. Porter, J. Gassenhuber, B. Obermaier, and T.D. Petes. 1995. TEL1, a gene involved in controlling telomere length in $S$. cerevisiae, is homologous to the human ataxia telangiectasia gene. Cell 82: 823-829.

Hari, K.L., A. Santerre, J.J. Sekelsky, K.S. McKim, J.B. Boyd, and R.S. Hawley. 1995. The mei-41 gene of $D$. melanogaster is a structural and functional homolog of the human ataxia telangiectasia gene. Cell 82: 815-821.

Hartwell, L.H. and D. Smith. 1985. Altered fidelity of mitotic chromosome transmission in cell cycle mutants of $S$. cerevisiae. Genetics 110: 381-395.

Kato, R. and H. Ogawa. 1994. An essential gene, ESRI, is required for mitotic cell growth, DNA repair and meiotic recombination in Saccharomyces cerevisiae. Nucleic Acids Res. 22: 3104-3112.

Klein, H.L. 1995. Genetic control of intrachromosomal recombination. BioEssays 17: 147-159.

Knudson, A.G., Jr. 1991. Overview: Genes that predispose to cancer. Mutat. Res. 247: 185-190.

Konrad, E.B. 1977. Method for the isolation of Escherichia coli mutants with enhanced recombination between chromosomal duplications. J. Bacteriol. 130: $167-172$.

Loeb, L.A. 1991. Mutator phenotype may be required for multistage carcinogenesis. Cancer Res. 51: 3075-3079.

Meyn, M.S. 1993. High spontaneous intrachromosomal recombination rates in ataxia-telangiectasia. Science 260: $1327-1330$.

Monnat, R.J., Jr. 1992. Werner syndrome: Molecular genetics and mechanistic hypotheses. Exp. Gerontol. 27: 447-453.

Morrow, D.M., D.A. Tagle, Y. Shiloh, F.S. Collins, and P. Hieter. 1995. TEL1, an S. cerevisiae homolog of the human gene mutated in ataxia telangiectasia, is functionally related to the yeast checkpoint gene MEC1. Cell 82: 831-840.

Parsons, R., G.M. Li, M.J. Longley, W.H. Fang, N. Papadopoulos, J. Jen, A. de la Chapelle, K.W. Kinzler, B. Vogelstein, and P. Modrich. 1993. Hypermutability and mismatch repair deficiency in RER + tumor cells. Cell 75: $1227-1236$.

Puranam, K.L. and P.J. Blackshear. 1994. Cloning and characterization of RECQL, a potential human homologue of the Escherichia coli DNA helicase RecQ. J. Biol. Chem. 269: 29838-29845.

Savitsky, K., A. Bar-Shira, S. Gilad, G. Rotman, Y. Ziv, L. Vanagaite, D.A. Tagle, S. Smith, T. Uziel, S. Sfez, et al.
1995. A single ataxia telangiectasia gene with a product similar to PI-3 kinase. Science 268: 1749-1753.

Smith, J. and R. Rothstein. 1995. A mutation in the gene encoding the Saccharomyces cerevisiae single-stranded DNA-binding protein Rfa 1 stimulates a $R A D 52$-independent pathway for direct-repeat recombination. Mol. Cell. Biol. 15: 1632-1641.

Tanaka, K. and R.D. Wood. 1994. Xeroderma pigmentosum and nucleotide excision repair of DNA. Trends Biochem. Sci. 19: 83-86.

Umezu, K., K. Nakayama, and H. Nakayama. 1990. Escherichia coli RecQ protein is a DNA helicase. Proc. Natl. Acad. Sci. 87: 5363-5367.

Wang, J.C. 1991. DNA topoisomerases: Why so many? J. Biol. Chem. 266: 6659-6662.

Watt, P.M., E.J. Louis, R.H. Borts, and I.D. Hickson. 1995. Sgs 1: A eukaryotic homolog of $E$. coli RecQ that interacts with topoisomerase II in vivo and is required for faithful chromosome segregation. Cell 81: 253-260. 


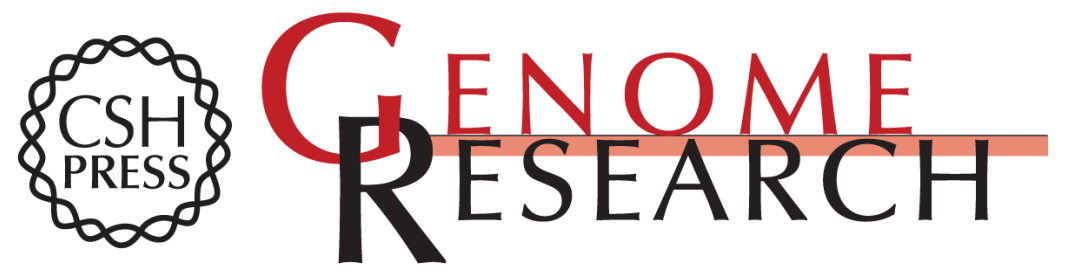

\section{Hyper-recombination and Bloom's syndrome: microbes again provide clues about cancer.}

R Rothstein and S Gangloff

Genome Res. 1995 5: 421-426

Access the most recent version at doi:10.1101/gr.5.5.421

References This article cites 30 articles, 11 of which can be accessed free at:

http://genome.cshlp.org/content/5/5/421.full.html\#ref-list-1

\section{License}

Email Alerting Receive free email alerts when new articles cite this article - sign up in the box at the Service top right corner of the article or click here.

\section{Affordable, Accurate Sequencing.}

To subscribe to Genome Research go to: https://genome.cshlp.org/subscriptions 